Peer-Reviewed Article

ISSN: 2162-3104 Print / ISSN: 2166-3750 Online Volume 7 Number 1 (2017), pp. 53-72 (C) Journal of International Students http://jistudents.org/

\title{
Factors Affecting the Academic and Cultural Adjustment of Saudi International Students in Australian Universities
}

\author{
Nisreen Alsahafi \\ University of New South Wales, Australia \\ Seong-Chul Shin \\ University of New South Wales, Australia
}

\begin{abstract}
The authors investigate factors affecting Saudi students' educational experiences in Australian universities and their adjustment issues. The data comes from the survey of 100 Saudi international students in Sydney and subsequent interviews. The analysis revealed that language proficiency is the main barrier to Saudi students' academic and social adjustment, with some academic factors such as classroom activities and assessment methods, and social factors such as homesickness and loneliness also affecting their study. The analysis has also identified Saudi students' coping strategies such as improvement of language competence, time management and mixing with others. It then discusses differences in perceived level of difficulty with respect to gender, age, educational level and length of residence, as well as some implications of the findings.
\end{abstract}

Keywords: Affecting factors, Australian universities, International education, Saudi students

International education is a great experience, which provides students with the opportunity to gain a number of valuable benefits. However, the literature demonstrates that international students experience the differences between their home culture and the new culture, which may have a great impact on their study. International students face a new learning environment, a foreign language, difficulties related to finance and 
accommodation, as well as different cultural aspects and norms (Borland \& Pearce, 2002; Poyrazli \& Grahame, 2007; Trice, 2007). These challenges tend to be more complex if the students' home culture is markedly different from the new culture. Although adjustment to a new learning environment is not an easy process, previous research shows that international students generally take a positive approach to overcome all the difficulties and they have the ability to adjust to the new environment (Vole \& Renshaw, 1996; $\mathrm{Wu}, 2011)$.

With the establishment of the King Abdullah Scholarships Program in 2005, there has been a significant increase in the number of Saudi students enrolled in Australian universities over the last few years, with about 10,000 Saudi government-sponsored students in 2011 (Ministry of Higher Education, 2012). Being supported financially by the government, Saudi students may not struggle with financial burdens but they face a new environment, which is vastly different from their home country, which may have a significant impact on their study.

Despite the significant increase in the number of Saudi students enrolled in Australian universities, very little research has been done to understand their experiences and how they bridge the cultural differences. Thus, this study sought to investigate the language and cultural difficulties facing Saudi students and the strategies they use to cope with the new environment. The findings of this study will greatly enhance the educational experiences of international students in general and Saudi international students, in particular. The findings will also assist education providers in Australia to make a better plan for international education.

\section{LITERATURE REVIEW}

\section{Language Issues Affecting International Students}

Studying in a non-native language is one of the main difficulties facing international students. Proficiency in the target language is a fundamental factor that enhances their academic achievement and cultural adjustment. Stoynoff (1997) examines the main factors affecting international students' academic performance and found that there is a correlation between their academic achievement and language proficiency. Based on another study by Lewthwaite (1996), lack of confidence in the language of instruction is one of the main frustrations that may face international students and their contribution inside the classroom. Many aspects of academic language barriers facing international students have been identified in previous studies (Robertson, Line, Jones, \& Thomas, 2000; Shin, 2011; Wong, 2004; Wu, 2011). For example, Wu (2011) investigates the difficulties faced by Taiwanese students enrolled in an 
American university and found that the main problems were related to written assignments, tests, the use of language, second language comprehension, note-taking, oral presentation and participation in class discussions. In her case study, Bifuh-Ambe (2009) summarizes the main difficulties faced by international students into four domains: the receptive and expressive language, written language such as written assignments and note-taking, comprehension such as understanding texts, and difficulties related to the methods of teaching and assessment in the host country.

Language barriers also affect international students in the social settings as they contribute to their socio-cultural adjustment. Besides the academic language, international students need to acquire the social language as well. They need to have competence in the language used in academic contexts as well as in informal, non-academic, contexts. Some international students may have sufficient level of language proficiency, which enhances their success academically, but they may avoid social interaction as a result of the lack of social language (Lewthwaite, 1996). Likewise, Trice (2007) attributes international students' isolation from domestic people to their weakness in language skills. Furthermore, lack of social language may also affect international students even inside classrooms. As Robertson et al. (2000) reported, one of the difficulties facing international students is the difficulty of understanding colloquial language, idioms, slang and the different accents used by their lecturers.

\section{Cultural Issues Affecting International Students}

Besides language proficiency, international students need to acquire cultural competence. Differences between cultures have a great impact on international students' academic and social lives. Borland and Pearce (2002) reported that international students' language knowledge without cultural competence is not sufficient to achieve success in both the academic and the social settings. One aspect of cultural differences is related to the differences in learning and teaching approaches, which hinder most of international students' adaptation to the new academic setting. The lack of familiarity with the learning approaches in the host country resulted in great challenges amongst international students in the academic context (Borland \& Pearce, 2002; Shin, 2011).

Loneliness has been reported as one of the problems that are most likely to impact international students' adaptation. Sawir, Marginson, Deumert, Nyland, and Ramia (2008) attribute cultural loneliness to being away from the familiar environment. According to Berry (1997), those who separate themselves from the new culture are more likely to experience a high level of cultural stress. When the home culture and the new one are vastly different, cultural stress becomes a big challenge (Thomson, Rosenthal, \& Russell, 2006). Making friends with students from the host 
culture is a difficulty that most international students encounter (Sawir et al., 2008; Sun \& Chen, 1999). Difficulty in making friends may lead to the feeling of homesickness, which is considered as one of the frequent concerns among international students (Kegel, 2009).

\section{Adaptation to the New Culture}

In order to gain their goals, international students do need to overcome the language and cultural challenges and to adjust to the new environment. Adaptation to the new culture may take five stages as suggested by Adler (1975): (a) contact with the new culture; (b) disintegration; (c) reintegration; (d) autonomy; and (e) interdependence. Different factors that enhance the adaptation process have been identified: self-efficacy and social support (Hechanova-Alampay, Beehr, Christiansen, \& Horn, 2002), familial support (Mittal \& Wieling, 2006; Poyrazli \& Kavanaugh, 2006), understanding the similarities and differences between the two cultures (Tseng \& Newton, 2002). Research shows that international students generally take a positive approach to overcome all the difficulties (Vole \& Renshaw, 1996).

International students' demographic characteristics may have an impact on their adaptation process, though there are no consistent findings. For example, in some studies, female students showed a higher level of stress (Kwon, 2009). Poyrazli and Lopez (2007) found that male students had a higher level of language difficulties. In contrast, some other studies revealed that gender had no impact on the adjustment process (Poyrazli, Arbona, Bullington, \& Pisecco, 2001; Yan \& Berliner, 2011). Age has also presented to have an effect on the adjustment process. Sumer, Poyrazli, and Grahame (2008) reported that younger students adapt to the new culture more easily, compared to older students. However, a study by Yan and Berliner (2011) revealed that younger students are more likely to experience cultural difficulties. Hofmann (2010) found that younger undergraduate students experience a higher level of language difficulties and cultural stress. It was also found that respondents who resided in the host country for two years had more cultural stress than those who resided for longer or shorter periods of time.

\section{Saudi International Students}

Saudi students' learning and culture backgrounds cannot contribute more to their academic success in Western universities. Shabeeb (1996) found that English language was the main difficulty affecting Saudi and Arabian Gulf students' adjustment process. Furthermore, Saudi students are accustomed to teaching and learning styles, which are different from the common teaching approaches in Western culture (Kampman, 2011). Another cultural aspect, which may have a great impact on Saudi 
international students, is the gender segregation aspect of Saudi culture. Male and female are segregated in schooling and universities. They attend separate schools and institutions and are taught by teachers from the same gender. Being in a non-segregated culture is considered as a new experience that Saudi students need to adapt to. A study by Shaw (2009) revealed that Saudi students in the US experience a different culture and unfamiliar learning styles. The major differences reported were: the mixed gender classes, the negotiation atmosphere of American classrooms, and the availability of different resources, and to bridge these differences, they use strategies such as setting their goals, developing study skills, study in groups and time management. Abdel Razek (2012) identified different factors that limit Saudi students' participation in the social life in America including religion, the mixed gender aspect of American culture and dietary restrictions. Al-Hazmi's study (2010) focused on the impact of Saudi gender segregation culture upon Saudi students in Australia. The study revealed that being in a mixed gender culture has an impact on Saudi students' cultural identity. The study is directed by the following research questions:

1. What are the language-associated activities that Saudi students experience difficulties with in Australian universities?

2. What are the cultural issues affecting Saudi students' in Australian universities?

3. Are there differences in the perceived level of language and cultural difficulties based on demographic factors among Saudi students in Australian universities?

4. What strategies do Saudi students use to overcome the language and cultural challenges they face?

\section{RESEARCH METHOD}

Mixed method research is defined as "research in which the investigator collects and analyzes data, integrates the findings, and draw inferences using both qualitative and quantitative approaches or methods in a single study or program of inquiry” (Tashakkori \& Creswell, 2007, p. 4). The rationale for integrating both quantitative and qualitative methods in this study is that using a single method is insufficient to address the complex issue of Saudi student experiences in Australia. Using the mixed method approach offers a better understanding of the research problem and provides richer data from the participants as the two methods complement each other (Creswell \& Clark, 2011; Valadez \& Bamberger, 1994).

The fieldwork for data collection was conducted in 2012, in a four-

month period. It was designed in two phases. In the first phase, a survey was developed and administered to a large sample to measure a number of 
language and cultural affecting factors and coping strategies considered important in the relevant literature. The second phase was a qualitative exploration of Saudi students' personal educational experiences in Australian universities using semi-structured interviews to gain more insight into the quantitative data. The results of the quantitative and qualitative data were integrated when discussing the findings of the study. 100 Saudi students enrolled in 17 different Australian universities participated in this study (See Table 1 for participants' backgrounds). Those who were still undertaking English as a second language courses were not included in this study as they did not have full academic experiences outside the ESL program.

\section{Table 1: Description of the participants' background}

\begin{tabular}{llc}
\hline \multicolumn{1}{c}{ Characteristics } & & No. \& \% (out of 100) \\
\hline \multirow{2}{*}{ Gender* } & $\mathrm{M}$ & 78 \\
& $\mathrm{~F}$ & 22 \\
\cline { 2 - 3 } Age & $18-23$ & 20 \\
& $24-26$ & 76 \\
Level of Education** & $27<$ & 22 \\
& $\mathrm{UG}$ & 78 \\
\hline \multirow{2}{*}{ Length of Residence (Years) } & $\mathrm{PG}$ & 24 \\
& $<2$ & 55 \\
& $2-4$ & 21 \\
\hline
\end{tabular}

*The numbers by gender reflect the proportion of male and female Saudi students studying in Australia as in year 2010-2011, there were 7,747 male students and 1,722 female students (Ministry of Higher Education, 2012).

**The numbers by level of education reflect the proportion of undergraduate and postgraduate Saudi students who are awarded scholarships as 8155 postgraduate students received scholarships in different countries in 2011 whereas the number of undergraduate students was 566 students (Ministry of Higher Education, 2012).

\section{Table 2: The examined factors and strategies}

\begin{tabular}{|c|c|}
\hline Language factors & $\begin{array}{l}\text { 1. Taking notes; 2. Participation in class discussions; } 3 \text {. Reading } \\
\text { texts/articles; } 4 \text {. Written assignments; } 5 \text {. Tests; } 6 \text {. Understanding } \\
\text { lectures; 7. Speaking in tutorials and seminars; } 8 \text {. Understanding } \\
\text { questions; and } 9 . \text { Writing reports. }\end{array}$ \\
\hline \multirow[t]{2}{*}{ Cultural factors } & $\begin{array}{l}\text { Academic factors: } \\
\text { 1. Classroom arrangement and activities; 2. Types of assessment } \\
\text { tools; 3. Availability of resources and facilities; 4. mix-gender } \\
\text { classes; 5. Relationship with lecturers; 6. Lecturers' role in } \\
\text { classroom; and 7. Student's role. }\end{array}$ \\
\hline & $\begin{array}{l}\text { Social factors: } \\
\text { 1. Loneliness; } 2 \text {. Homesickness; } 3 \text {. Mixing with others from different } \\
\text { cultures; 4. Unfamiliar customs; } 5 \text {. Discrimination; 6. Food; } 7 . \\
\text { Climate. }\end{array}$ \\
\hline Coping strategies & $\begin{array}{l}\text { 1. Improving language; } 2 \text {. Making friends with people from other } \\
\text { cultures; } 3 \text {. Time management; } 4 \text {. Participating in different activities; } \\
\text { 5. Increasing knowledge about the new culture; } 6 \text {. Building good } \\
\text { relationships with the academic advisors; } 7 \text {. Asking others for help; } \\
\text { 8. Study in groups; and } 9 \text {. Using the available resources. }\end{array}$ \\
\hline
\end{tabular}




\section{Data Collection and Analysis}

Survey instrument. An online questionnaire was designed using a survey software tool to collect data from participants about their experiences in Australian universities. The questionnaire was constructed around 9 language factors, 7 cultural factors, and 9 coping strategies. The factors and strategies were adopted from the relevant literature (Bifuh-Ambe, 2009; Sawir et al., 2008; Shaw, 2009; Shin, 2011; Trice, 2007; Tseng \& Newton, 2002) based on their relevance and importance to the research questions of the study. The examined factors and strategies are presented in Table 2.

The first section of the survey asked a series of demographic questions about gender, age, level of education, and length of stay. In the next sections of the survey, a five-point Likert scale was used to measure the level of difficulty experienced with each of the examined factors as well as the level of helpfulness of each of the examined coping strategy. Different response scales were used in each section. Frequency scales (5-always, 4usually, 3-sometimes, 2-rarely and 1-never) were used to measure the level of language difficulties, level of problem scales (5-very problematic, 4problematic, 3-not sure, 2-hardly problematic,1-not problematic at all) were used to rate the level of problem experienced with the examined cultural factors, and level of helpfulness scales (5-very helpful, 4-helpful, 3-not sure, 2-hardly helpful, 1-not helpful at all) were used to measure the level of helpfulness of the examined coping strategies. At the end of the questionnaire, respondents were invited to take part in follow-up interviews and asked to provide their details (name and contact details) if they are interested in taking part in the interviews.

After obtaining ethics approval, the researchers sent an email to the Saudi students' Club in Sydney to seek their assistance to distribute the questionnaire link to all Saudi international students who were studying in different Australian universities. After obtaining the agreement, an email invitation to participate in the online survey questionnaire was forwarded to the Club President, who then circulated it to all Saudi students in Australia. The body of the email included a clickable hyperlink to the survey. They were provided with clear details about the study and its purposes. They were assured of their privacy and confidentiality. 100 responses were received.

To analyze the quantitative data, responses to the survey exported into an excel spreadsheet, and then transferred to SPSS software. The data analysis included descriptive statistics (mean and standard deviation) and one-way ANOVA. The mean scores were used to determine the overall level of difficulty experienced with each examined factor as well as the overall level of helpfulness of each of the examined coping strategies (RQ1, 2 and 4). The maximum possible mean score for each factor/strategy was 5 (1-2.33 indicate a low level, 2.34-3.66 indicate a moderate level, and 3.67- 
5.00 indicate a high level). To answer RQ 4, the data analysis procedure involved a comparison of means through one-way ANOVA to explore whether differences between the means of the overall level of difficulties based on the selected demographic factors were significant.

Semi-structured interviews. Qualitative data were collected using semi-structured interviews with 7 students selected from those who indicated their willingness in participating in the interviews. Participants were selected to present a sample of Saudi students with different demographic factors. Interviewees were contacted by email to arrange an appropriate time. English was the language used mainly for the interview with 5 of the participants, and Arabic was used with 2 of the participants. Interviews were conducted by phone with 7 students. Choosing to administer the interviews by phone was for two reasons. Firstly, this method helps reach the participants quickly with the time limit and to collect data most economically. As pointed out by Crano and Brewer (2002), telephone interviews can be accomplished with greater speed, compared to personal interviews. Secondly, the participants indicated their preference in conducting the interviews via phone.

Pre-determined open-ended questions were used as an interview guide to ensure the covering of the important issues. Participants were asked about the main difficulties faced during their study and the main strategies they adopt to overcome these difficulties (see Appendix A). They were given the opportunities to freely talk about their experiences. The length of the interviews ranged from 20-30 minutes and all of them were audio-taped and then transcribed. In order to maintain anonymous, letters (A-G) were assigned to the participants.

The qualitative data were analyzed in different steps (King \& Horrocks, 2010; Mason, 2002). Firstly, the interviews conducted in Arabic were translated to English. Secondly, the interview transcripts were read several times literally and interpretively. Thirdly, the significant statements and sentences were identified, coded and categorized under key themes formulated through the related literature. Fourthly, the themes were connected and interrelated. Finally, the main themes were discussed to give more insight into the statistical analysis.

\section{RESULTS}

\section{Quantitative Data}

Affecting language and cultural factors. The mean sores indicated that the overall level of difficulty experienced with language was in moderate level $(M=2.96)$. The highest level of language difficulties was experienced in 
written assignments and participation in class discussions. On the other hand, understanding questions and understanding lectures were perceived as the least difficult activities. Table 3 illustrates the mean of the experienced level of difficulty with the examined

Table 3: The means of the level of difficulty with the language-associated activities

\begin{tabular}{lcc}
\hline Language-associated activities & Mean & SD \\
\hline Written assignment & 3.21 & 1.09 \\
Participation in class discussions & 3.06 & 1.05 \\
Writing reports & 3.00 & 1.02 \\
Tests & 2.99 & 1.05 \\
Taking notes & 2.97 & 1.07 \\
Reading texts/articles & 2.96 & 1.00 \\
Speaking in tutorials & 2.84 & 1.10 \\
Understanding questions & 2.83 & 0.97 \\
Understanding lectures & 2.74 & 1.03 \\
Overall & 2.96 & 0.71 \\
\hline
\end{tabular}

With respect to the cultural factors, the data revealed that, overall, the level of difficulty experienced with the cultural factors, both academic and social, examined in this study was not high. The level of difficulty experienced with the examined academic and with the examined social factors was in moderate level (M-2.51 and 2.34, respectively). However, the level of difficulty with the social factors was somewhat greater when compared to the academic factors. There were noticeable differences between the levels of difficulty perceived in each factor. The main problematic academic factors were types of assessment tools and classroom arrangement and activities, while the most problematic social factors were loneliness, homesickness and discrimination. Table 4 presents the mean scores of the experienced level of difficulty with the cultural factors.

Table 4: The means of the level of difficulty with the cultural factors

\begin{tabular}{lll|lcc}
\hline \multicolumn{1}{c}{ Academic factors } & Mean & SD & \multicolumn{1}{c}{ Social factors } & Mean & SD \\
\hline Types of assessment tools & 2.97 & 1.13 & Loneliness & 2.90 & 1.34 \\
Classroom arrangement and activities & 2.42 & 1.16 & Homesickness & 2.88 & 1.39 \\
Your relationship with lecturers & 2.33 & 1.16 & Discrimination & 2.80 & 1.36 \\
Availability of resources \& facilities & 2.28 & 1.25 & Unfamiliar customs & 2.43 & 1.17 \\
Lecturer's role in classroom & 2.26 & 1.19 & Food & 2.31 & 1.31 \\
Your role as a student in classrooms & 2.21 & 1.17 & Mixing with others & 2.21 & 1.27 \\
Mixed gender classes. & 1.92 & 1.24 & Climate & 2.04 & 1.16 \\
Overall & 2.34 & 0.80 & Overall & 2.51 & 0.85 \\
\hline
\end{tabular}


Differences in the level of perceived difficulty based on the demographic factors. The analysis indicated significant differences in the level of language difficulties based on age $(\mathrm{F}=3.28, \mathrm{p}<.05)$. No significant differences were found in the level of language difficulties based on the other demographic factors (gender, level of education and length of stay). Table 5 presents differences in the level of difficulty with language based on demographic factors.

Table 5: Differences in the level of difficulty with language based on demographic factors

\begin{tabular}{llllll}
\hline Demographic factors & & $\mathrm{M}$ & $\mathrm{SD}$ & $\mathrm{t} / \mathrm{F}$ & $\mathrm{s}$ sig \\
\hline \multirow{2}{*}{ Gender } & $\mathrm{M}$ & 2.96 & 0.71 & \multirow{2}{*}{0.19} & \multirow{2}{*}{0.66} \\
\cline { 2 - 6 } Age & $\mathrm{F}$ & 2.95 & 0.73 & & \\
\cline { 2 - 6 } & $18-23$ & 3.61 & 0.97 & & \multirow{2}{*}{0.04} \\
\multirow{3}{*}{ Level of Education } & $24-26$ & 3.11 & 0.61 & 3.28 & \multirow{2}{*}{0.22} \\
& $27<$ & 2.88 & 0.70 & & \multirow{2}{*}{0.45} \\
\cline { 2 - 6 } Length of stay (Years) & $\mathrm{UG}$ & 3.15 & 0.73 & \multirow{2}{*}{1.51} & \\
& $\mathrm{PG}$ & 2.90 & 0.69 & & \\
\cline { 2 - 6 } & $<2$ & 3.07 & 0.62 & \multirow{2}{*}{0.80} & \\
\hline
\end{tabular}

Table 6: Differences in the level of difficulty with cultural factors based on demographic factors

\begin{tabular}{|c|c|c|c|c|c|c|c|c|c|}
\hline \multirow{2}{*}{ Demographic factors } & & \multicolumn{4}{|c|}{ Academic factors } & \multicolumn{4}{|c|}{ Social factors } \\
\hline & & $\mathrm{M}$ & SD & $t / f$ & sig & $\mathrm{M}$ & SD & $t / f$ & sig \\
\hline \multirow{2}{*}{ Gender } & $\mathrm{M}$ & 2.35 & 0.84 & \multirow{2}{*}{-0.09} & \multirow{2}{*}{0.92} & 2.44 & 0.83 & \multirow{2}{*}{1.76} & \multirow{2}{*}{$\begin{array}{l}0 . \\
08\end{array}$} \\
\hline & $\mathrm{F}$ & 2.30 & 0.66 & & & 2.77 & 0.89 & & \\
\hline \multirow{3}{*}{ Age } & $18-23$ & 2.89 & 1.57 & \multirow{3}{*}{1.72} & \multirow{3}{*}{0.18} & 2.96 & 1.35 & \multirow{3}{*}{0.59} & \multirow{3}{*}{$\begin{array}{l}0 . \\
56\end{array}$} \\
\hline & $24-26$ & 2.53 & 0.69 & & & 2.56 & 0.97 & & \\
\hline & $27<$ & 2.26 & 0.77 & & & 2.47 & 0.79 & & \\
\hline \multirow{2}{*}{ Level of Education } & UG & 2.45 & 0.77 & \multirow[t]{2}{*}{0.76} & \multirow[t]{2}{*}{0.45} & 2.37 & 0.81 & \multirow{2}{*}{-0.76} & \multirow{2}{*}{$\begin{array}{c}0 . \\
45 \\
\end{array}$} \\
\hline & PG & 2.31 & 0.82 & & & 2.55 & 0.86 & & \\
\hline \multirow{3}{*}{ Length of stay (Years) } & $<2$ & 2.19 & 0.75 & \multirow{3}{*}{0.82} & \multirow{3}{*}{0.44} & 2.36 & 0.74 & \multirow{3}{*}{1.99} & \multirow{3}{*}{$\begin{array}{l}1 . \\
14\end{array}$} \\
\hline & $2-4$ & 2.44 & 0.82 & & & 2.66 & 0.84 & & \\
\hline & $4<$ & 2.26 & 0.83 & & & 2.27 & 0.93 & & \\
\hline
\end{tabular}

With respect to the cultural factors, the analysis revealed that no significant differences between the overall experienced level with cultural factors, academic and social, based on the selected demographic factors. Table 6 presents differences in the level of difficulty with cultural factors based on demographic factors. 
Coping strategies. Overall, the mean scores indicated that the perceived helpfulness with the examined strategies was in high level $(M=3.93)$. Improving language, time management, and using the available resources were perceived as the most helpful strategies. Table 7 illustrates the mean scores of the level of helpfulness of each strategy.

Table 7: The means of the level of the helpfulness of coping strategies

\begin{tabular}{lcc}
\hline Coping strategies & Mean & SD \\
\hline Improving language & 4.28 & 0.83 \\
Time management & 4.16 & 0.19 \\
Using the available resources & 4.15 & 0.80 \\
Making friends with people from other cultures & 4.07 & 0.90 \\
Increasing knowledge about the new culture & 3.93 & 0.99 \\
Asking others for help & 3.79 & 0.49 \\
Participating in different activities & 3.76 & 1.03 \\
Building good relationships with academic advisors & 3.61 & 1.06 \\
Study in groups & 3.59 & 1.24 \\
Overall & 3.93 & 0.57 \\
\hline
\end{tabular}

\section{Qualitative Data}

Qualitative data were categorized into three major themes: language challenges, cultural challenges and coping strategies.

Language challenges: Participants indicated that they experienced some difficulties with language, though they did not perceive it as a big barrier. When asking whether the students regarded the language as a barrier, one response was "It is not very much as a barrier because I can understand a lecture and I can still answer the questions...but I still have language difficulties”.

The perceived difficulty with language was reported to be associated mainly with expressive language with both oral and written language. One of the interview responses was "I feel sometimes like I cannot express my ideas enough, particularly, in practical, oral exam and oral presentation". Another participant responded "When I sit and read the questions to start to write the answer... there are some limitations limit me to write in an academic way, in the way that in the Master level”.

Participants reported also some difficulties with receptive language in terms of reading texts and articles. One of the responses was:

I still have some difficulties with some of the scientific words or scientific terminology...I have to, you know, nearly if it is a new subject, I have to check nearly more than $10-15$ words in one page, 
just because I want to understand all the details of this subject...I need an hour to finish three pages in a chapter.

Cultural Challenges. Perceived difficulty with cultural factors indicated in the qualitative data was categorized under academic challenges and social challenges.

Academic challenges. Participants indicated that they experienced some academic difficulties with assessment tools, mainly with tests and oral presentations. One participant stated, "The most difficult thing is the multiple choice questions in the test. For example, you may have 60-70 questions. You need to understand everything in the book”. Another participant said:

The most difficult one is exams or tests especially when Australian style emphasizes on your time management more than on your knowledge. They give you a little bit of time; let's say an hour, to finish 40 or 50 questions.

With regards to oral presentation, one participant mentioned:

... I do not have the full confidence to present my work in front of people, so maybe this one is like a bit challenging...I am not used to present in front of people. It is more than confidence, more than a language for me.

Most participants attributed their perceived difficulty with academic factors to their prior learning experiences. They pointed out to some of the differences between studying in their home country and studying in Australia that caused some academic challenges for them. One participant said, "The main difference is the focus on research. Unlike in Saudi Arabia, you cannot depend on a book or a lecture. You have to work on your own, to read a lot to get a good grade". Another participant stated, "In Saudi Arabia, the teacher is the source of knowledge whereas in Australia, the student needs to search about knowledge. This difference is the main difficulty I faced here in Australia”.

Differences between studying in their home country and studying in Australia were also reported to cause some academic challenges in terms of classroom activities. One student stated, "They focus more here on practical activities more than theoretical, but in Saudi Arabia, they focus on theoretical rather than practical". Another participant said, "Here, they have a strategy called tutorials... but in Saudi Arabia, we do not have such tutorials. We just attend a lecture or a class” 
Social challenges. Participants indicated that they experienced some of cultural challenges especially homesickness and loneliness. Some of the statement made include, "I do miss my family; I do miss my mother and everything. Well, here you have just to keep an eye on the ball. You have to stay focus on your study" and "Sometimes, I feel lonely because here they have their own life style...I cannot be like them because of the religion, because...even their thinking style, the way of thinking is different from us".

Interview responses showed that most participant experienced cultural stress at the beginning, but they could adapt to the new culture later. One of the statements made was: "At the beginning, I felt homesick. But after two or three months, I adapted to the new culture". Another statement was,

Being in a new culture affected my study so much at the beginning especially in the first year because of the cultural differences. But to some extent, I am OK now. Going to Saudi Arabia from one time to another helps me much.

Interview responses indicated that there was no difficulty faced with mixing with others especially when having a good language level. However, some of the responses indicated the preference of having friends from the same cultures. One participant stated, "I prefer to have friends from my culture, not necessary from Saudi Arabia, but at least, they can speak my language. I can have relief. I can express myself easily without any difficulties”. Another participant said:

At the beginning, it was difficult because of difficulty with the language. With a very low level of language proficiency, it is difficult to contact with natives. But with the improvement in language, it became ok. But still I meet with people from my culture in our cultural celebrations.

Coping Strategies. Improving language was indicated as a very helpful strategy to enhance their academic performance and to cop with the new culture. One student stated, "The most important thing is language. Once I have the good language to communicate, I will be good at communicating with people. I will not be isolated...I will not have any barriers”.

Participants identified some other strategies that helped them to adapt to the new culture both academically and socially such as using of the available resources, celebrating specific cultural occasions with people from the same culture and mixing with others. Some of the statement made included "in the academic context, I prefer to work independently, I try to depend on 
myself and use the available recourses", "Mixing with others from different cultures helps to adjust to the new culture", and "Attending special cultural celebrations with people from the same culture helps me reduce stress".

\section{DISCUSSION}

The quantitative and qualitative data indicated that Saudi students experience difficulties mainly with expressive and written language. Respondents reported spending extra time for doing their assignments or studying due to the lack of language competence. This finding is consistent with the findings of other research concerned with international students or Saudi students, in particular. Stoynoff (1997) found that there is a correlation between international students' academic achievement and their language competence. Similarly, Shabeeb's study (1996) that investigates Saudi and Arabian Gulf students' adaptation problems revealed that English language was the main difficult area facing their adjustment process. The current study also indicated that language barriers affect the respondents even in their social life and their contacts with others. This is confirmed by the findings of previous research (Lewthwaite, 1996; Trice, 2007).

With regard to cultural factors, the findings revealed that respondents did not have a high level of difficulty with the cultural factors. However, a greater level of difficulty was experienced with the social factors, compared to the academic factors. The highest level of academic difficulty was experienced in types of assessment tools and classroom activities. Tests and oral presentations were reported as the most difficult types of assessment tools. Beside lack of language competence, difficulties with the academic factors, as the qualitative data indicated, are associated with Saudi students' prior learning experiences and unfamiliarity with the education style in Australia. Saudi students are more accustomed to a teacher-centered teaching style and to memorization strategies in testing as pointed by Vassall-Fall (2011). Additionally, preparing and presenting an oral report is not widely practiced in Saudi Arabia, as the assessment system is more examination based. This may lead to a lack of confidence among Saudi students to present in front of others in class. This finding is consistent with the findings of a study by Kampman (2011) who has pointed out that Saudi students are accustomed to passive learning styles, which make it difficult for them to adapt to the teaching styles that encourage creativity and critical thinking. It also concurs with other studies (Shin, 2011; Sun \& Chen, 1999; Wong, 2004).

As to the social factors, the findings indicated that respondents experienced some aspects of cultural stress especially in their initial semesters. It was found that loneliness, homesickness and discriminations were the main problematic factors. These findings concur with the findings 
of previous research (Poyrazli \& Lopez, 2007; Sawir et al., 2008; Yue, 2012). The findings also indicated that respondents faced some difficulties in making friends from other cultures due to certain barriers, such as lack of language proficiency and cultural differences such as differences in preferred food, social and religious activities. This finding goes in line with the findings of a recent study done by Abdel Razek (2012) that Saudi students' participation in the social life in America is very limited due to different reasons such as religion, mix-gender aspect and dietary restrictions. It is also supported by the findings of another study by Yue (2012) concerned with international students' experience in Australia.

The study revealed significant differences in the perceived level of language difficulty based on age, which concurs with the findings of a study done by Hofmann (2010) which found that younger students experienced language difficulty more frequently than older students. On the other hand, the study showed no significant differences between the experienced language difficulty based on gender, level of education and length of stay. This is inconsistent with the findings of a study conducted by Poyrazli and Lopez (2007) as they found that female international students had higher level of English proficiency than male students and the researchers attributed this to their willingness to establish relationships with others, which create opportunities to practice the language. In the case of Saudi female students, it could be difficult for them to build relationships with others as they come from a segregated culture even in their social lives. No significant differences were found between the experienced level of cultural challenges based on the examined demographic factors (gender, age, level of education and length of stay). This finding concurs with the findings of previous studies (Abdullah, Adebayo, \& Talib, 2015; Yan \& Berliner, 2011).

In relation to coping strategies, improving language was the main strategy that helped the respondents to adapt to the new culture. This result was expectable as lack of language proficiency was reported to be one of the main factors affecting their adjustment. Other strategies such as time management, using of available resources, and celebrating specific cultural occasion were also found to be very helpful strategies. It was also evident that Saudi students try to take the advantages of both mixing with others from different cultures and with people from the same culture. Both of these strategies have their advantages. Having friends from different cultures can help in understanding other cultures, which facilitates the adaptation process. On the other hand, having friends from the same culture helps in gaining the social support, which helps decrease the effect of the cultural stress such as homesickness and loneliness. These coping strategies are also highlighted in previous research (Shaw, 2009; Tseng \& Newton, 2002). 


\section{CONCLUSIONS AND IMPLICATIONS}

Students' language competence, especially in expressive and written language, plays a significant role in their academic and social adjustment process. Saudi students' academic performance was affected mainly by classroom activities and assessment methods that require practical use of language such as tutorial discussion and oral presentation. Socially, Saudi students were most affected by such cultural factors as homesickness, loneliness and discrimination. The students coped with difficulties by improving their language skills, by exerting study skills (e.g. time management) and/or by attempting socio-cultural skills (e.g. mixing with others). While there were significant differences in the perceived level of language difficulties based on age, there were no significant differences found based on the other factors. Similarly, there were no significant differences between the perceived levels of cultural difficulties based on the demographic factors.

The study has a number of implications. For Saudi and other Arabian Gulf international students, the study reinforces the importance of having a high level of English proficiency as well as cultural competence, awareness of different educational approaches and provisions for challenges and socio-cultural difficulties. For sponsors and education providers, the findings highlight the importance of orientation programs for future students before coming to Australia about life and study in Australia with a particular focus on the main differences in the education systems and learning/teaching approaches. A further implication may be a question of what social activities will be effective for students' cultural adjustments and how effectively students can be encouraged to participate in those activities. A further research is required to find out specific areas of difficulties in language, academic and so-cultural domains, as well as ways of helping Saudi international students adjust to a new environment.

\section{REFERENCES}

Abdel Razek, A. (2012). An exploration of the case of Saudi students' engagement, success and self-efficacy at a Mid-Western American university. (Doctor of Education dissertation), University of Akron. Retrieved from https://etd.ohiolink.edu/

Abdullah, M., Adebayo, A., \& Talib, A. (2015). Relationship between demographic factors, social support and sociocultural adjustment among international post graduate students in a Malaysian public University. Journal of Educational and Social Research, 5(2), 8792. 
Adler, P. (1975). The transitional experience: An alternative view of culture shock. Journal of Humanistic Psychology, 15(4), 13-23. doi:10.1177/002216787501500403

Berry, J. (1997). Immigration, acculturation and adaptation. Applied Psychology: An International Review, 46(1), 5-34. doi:10.1111/j.1464-0597.1997.tb01087.x

Bifuh-Ambe, E. (2009). Literacy skills acquisition and use: A study of an English language learner in a U.S. university context. Adult Basic Education and Literacy Journal, 3(1), 24-33.

Borland, H., \& Pearce, A. (2002). Identifying key dimensions of language and cultural disadvantage at university. Australian Review of Applied Linguistics, 25(2), 101-127.

Crano, W., \& Brewer, M. (2002). Principles and Methods of Social Research (2nd ed.). Mahwah, NJ, US: Lawrence Erlbaum Associates.

Creswell, J., \& Clark, V. (2011). Designing and conducting mixed methods research. Thousand Oaks, CA: Sage Publications.

Hechanova-Alampay, R., Beehr, T., Christiansen, N., \& Horn, R. V. (2002). Adjustment and strain among domestic and international student sojourners: A longitudinal study. School Psychology International, 23(4), 458-474. doi:10.1177/0143034302234007

Hofmann, P. N. (2010). Examining factors of acculturative stress on international students as they affect utilization of campus-based health and counseling services at four-year public universities in ohio. (Doctoral dissertation), Bowling Green State University. Retrieved from http://search.proquest.com/docview/1651842866?accountid=12763 Eric database. (1651842866)

Kampman, D. (2011). From Riyadh to Portland: The study abroad experiences of five Saudi Arabian female students. (MA dissertation), SIT Graduate Institute, SIT Digitial Collection. Retrieved from http://digitalcollections.sit.edu/ipp_collection/512

Kegel, K. (2009). Homesickness in International College Students. In G. R. Walz, J. C. Bleuer, \& K. Y. R (Eds.), Compelling counseling interventions: VISTAS 2009 (pp. 67-76). Alexandra, VA: American Counseling Association.

King, N., \& Horrocks, C. (2010). Interviews in qualitative research. London: SAGE.

Kwon, Y. (2009). Factors affecting international students' transition to higher education institutions in the United States-from the perspective of office of international students. College Student Journal, 43(4), 1020-1036. 
Lewthwaite, M. (1996). A Study of international students' perspectives on cross-cultural adaptation International Journal for the Advancement of Counseling, 19(2), 167-185. doi:10.1007/BF00114787

Mason, J. (2002). Qualitative researching. London: SAGE.

Ministry of Higher Education. (2010). Students Abroad: Statistics Indicators and Analysis.Retrieved from < ohe.mohe.gov.sa/ar/Documents/Students\%20Abroad.pdf >.

Ministry of Higher Education. (2012). Higher education statistics. Retrieved from <http://www.mohe.gov.sa/ar/Ministry/DeputyMinistry-for-Planning-and-Information-

affairs/HESC/Pages/default.aspx>

Mittal, M., \& Wieling, E. (2006). Training experiences of international doctoral students in marriage and family therapy. Journal of Marital and Family Therapy, 32(3), 369-383.

Poyrazli, S., Arbona, C., Bullington, R., \& Pisecco, S. (2001). Adjustment issues of Turkish college students studying in the United States. College Student Journal, 35(1), 52-62.

Poyrazli, S., \& Grahame, K. (2007). Barriers to adjustment: Needs of international students within a semi-urban campus community. Journal of instructional Psychology, 34(1), 28-45.

Poyrazli, S., \& Kavanaugh, P. R. (2006). Marital status, ethnicity, academic achievement, and adjustment strains: The case of graduate international students. College Student Journal, 40(4), 767-781.

Poyrazli, S., \& Lopez, M. (2007). An exploratory study on perceived discrimination and homesickness: A comparison of international students to the U.S. Students. The Journal of Psychology, 141(3), 263-280. doi:10.3200/JRLP.141.3.263-280

Robertson, M., Line, M., Jones, S., \& Thomas, S. (2000). International students, learning environments and perceptions: A case study using the Delphi technique. Higher Education Research and Development, 19(1), 89-102. doi:10.1080/07294360050020499

Sawir, E., Marginson, S., Deumert, A., Nyland, C., \& Ramia, G. (2008). Loneliness and international students: an Australian study. Journal of Studies in International Education, 12(2), 148-180. doi:10.1177/1028315307299699

Shabeeb, S. (1996). Saudi and Arabian gulf students' adjustment problems in Eastern Washington. (PhD diss), Gonzaga University, Pro Quest Dissertations and Theses.

Shaw, D. (2009). Bridging differences: Saudi arabian students reflect on their educational experiences and share success strategies. (PhD diss), Oregon State University.

Shin, S.-C. (2011). Cross-Cultural Factors Affecting Korean Students' Study at Australian Universities. Paper presented at the Korean Studies in 
Shift-Proceedings of the 2010 Pacific-Asia Conference on Korean Studies, University of Auckland.

Stoynoff, S. (1997). Factors associated with international students' academic achievement. Journal of instructional Psychology, 24(1), 56-68.

Sumer, S., Poyrazli, S., \& Grahame, K. (2008). Predictors of depression and anxiety among international students. Journal of Counseling and Development, 86(4), 429-437. doi:10.1002/j.15566678.2008.tb00531.x

Sun, W., \& Chen, G. M. (1999). Dimensions of difficulties mainland Chinese students encounter in the United States. Intercultural Communication Studies, 9, 19-30.

Tashakkori, A., \& Creswell, J. (2007). The New Era of Mixed Methods. Journal of Mixed Methods Research, 1(1), 3-8.

Thomson, G., Rosenthal, D., \& Russell, J. (2006). Cultural stress among international students at an Australian university. Paper presented at the the Australian International Education Conference, Australia.

Trice, A. (2007). Faculty perspectives regarding graduate international students' isolation from host national students. International Education Journal, 8(1), 108-117. Retrieved from http://iej.com.au

Tseng, W., \& Newton, F. (2002). International students' strategies for wellbeing. College Student Journal, 36(4), 591-598.

Valadez, J., \& Bamberger, M. (1994). Monitoring and evaluating social programs in developing countries: A handbook for policymakers, managers and researchers. Washington, DC: The World Bank.

Vassall-Fall, D. (2011). Arab Students' Perceptions of Strategies to Reduce Memorization. AWEJ, 2(3), 48-69

Vole, S., \& Renshaw, P. (1996). Chinese students at an Australian university: Adaptability and continuity. In D. A. Watkins \& J. B. Biggs (Eds.), The Chinese Learner: Cultural, Psychological, and Contextual Influences (pp. 205-220). Hong Kong: Comparative Education Research Centre.

Wong, J. K. (2004). Are the learning styles of Asian internationals culturally or contextually based? International Education Journal, 4(4), 154166. Retrieved from http://iej.cjb.net

$\mathrm{Wu}$, I. J. (2011). Learning strategies use by international students from Taiwan in a university context: A case study. (MA diss), California State University, Chico.

Yan, K., \& Berliner, D. (2011). An examination of individual level factors in stress and coping processes: Perspectives of Chinese international students in the United States. Journal of College Student Development, 52(5), 523-542. doi:10.1353/csd.2011.0060 
Yue, Y. (2012). Health and wellbeing of international students in an Australian tertiary context. (Doctoral dissertation), University of Tasmania. Retrieved from http://eprints.utas.edu.au/id/eprint/15009

NISREEN ALSAHAFI, is currently completing a PhD in Linguistics in the Faculty of Arts and Social Sciences at the University of New South Wales. Email: n.alsahafi@student.unsw.edu.au

SEONG-CHUL SHIN, PhD, is a Senior Lecturer in the School of Humanities and Languages. His research interests include error analysis, socio-linguistic issues in L2 contexts and other topics such as L2 pedagogy and curriculum planning. Email: s.shin@unsw.edu.au

Manuscript submitted: April 15, 2015

Manuscript revised: November 2, 2015 Accepted for publication: February 21, 2016 